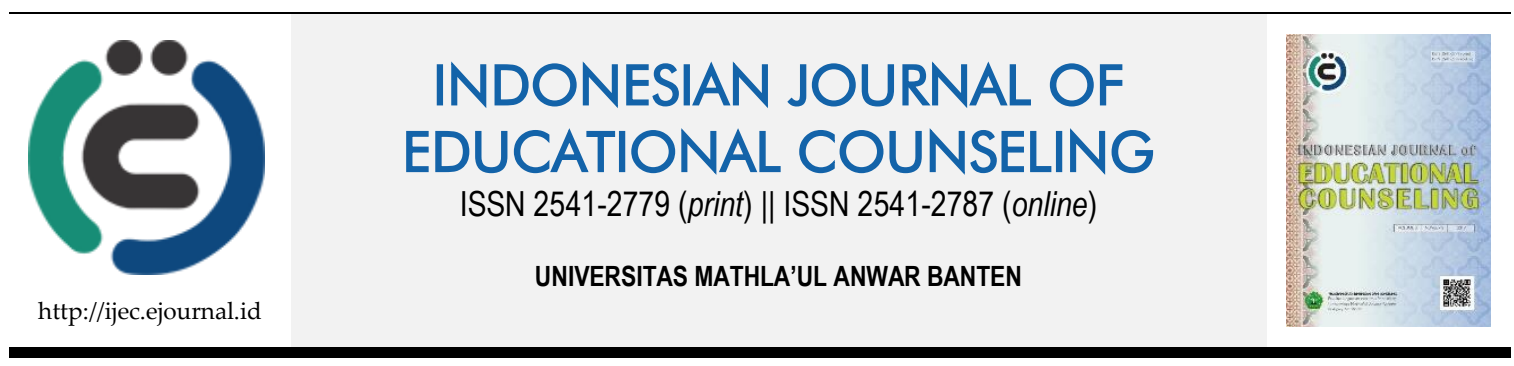

Research Based Article

\title{
Analisis Pemodelan Rasch: Skala Tatapikir Kedamaian Siswa
}

\author{
Dadang Sudrajat ${ }^{1}$, Sunaryo Kartadinata ${ }^{2}$, Uman Suherman ${ }^{3}$ \\ 1, 2, 3 Universitas Pendidikan Indonesia
}

\begin{tabular}{ll}
\hline Article History & ABSTRACT \\
\hline Received: 25.03.2019 & RASCH MODELING ANALYSIS: SCALE OF STUDENT PEACE OF \\
Received in revised form: & MINDSET. This study aims to develop a scale of early detection of peace \\
01.04.2019 & thinking in the context of standardized Indonesian culture. The study using a \\
Accepted: 10.04.2019 & descriptive method for 1118 students from several public high schools in \\
Available online: 05.08.2019 & Bandung through Rasch modeling analysis. It is reported that all items are \\
& correctly perceived by students, with excellent internal consistency and good \\
& unidimensionality. The implication shows that there is still a need for further \\
& scale research based on a more diverse level of education units, including \\
& among santri (student) in Islamic boarding schools (pesantren) so that the \\
& results are conclusive and comprehensive, with urban or rural backgrounds. \\
& This research explains a dynamic, progress, and a second stage that is good in \\
& developing TNT's scale into an ethnically diverse Indonesian context.
\end{tabular}

KEYWORDS: Internal Consistency, Rasch Modeling, Unidimensionality.

DOI: $10.30653 / 001.201933 .102$

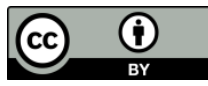

This is an open access article distributed under the terms of the Creative Commons Attribution 4.0 International License, which permits unrestricted use, distribution, and reproduction in any medium, provided the original work is properly cited. (c) 2019 Dadang Sudrajat, Sunaryo Kartadinata, Uman Suherman.

\section{PENDAHULUAN}

Sejak tahun 1920-an, Ki Hadjar Dewantara sebagai salah seorang Tokoh Pendidikan Nasional di Indonesia telah mempertegas pentingnya pendidikan berasaskan tertib dan damai. "Ketertiban tidak akan terdapat kalau tak bersandar pada kedamaian. Sebaliknya, tak akan ada orang hidup damai, jika ia dirintangi dalam segala syarat kehidupannya. Namun tertib dan damai yang tercipta di sekolah harus bebas dari paksaan, yang difasilitasi melalui metode among yang sangat demokratis" (Majelis Luhur Persatuan Tamansiswa, 2013, p. 48). Makna tertib dan damai merujuk pada keadaan dinamis, dan bebas dari adanya tindakan ketidakadilan.

Proses metamorfosis perkembangan konsep pedagogi kedamaian di Indonesia, selayaknya memperhatikan sekaligus dianggap sebagai salah satu komponen penting bertemali dengan diskursus pendidikan yang berkualitas. Selain itu, pengkajian mendalam atas pedagogi kedamaian merujuk pada upaya implementasi pendidikan kedamaian yang strukturnya sejalan dengan berbagai program yang diselenggarakan

${ }^{1}$ Corresponding author's address: Departemen Psikologi Pendidikan dan Bimbingan Universitas Pendidikan Indonesia; Jl. Dr. Setiabudi No.229, Isola, Kec. Sukasari, Kota Bandung, Jawa Barat 40154, Indonesia; Email: d-sudrajat@upi.edu 
oleh UNICEF melalui Millennium Development Goals (MDG, 2000) dan implementasi poin ke-16 "Sustainable Development Goals (SDGs)" tentang "Peace, Justice, and Strong Institutions -Promote peaceful and inclusive societies for sustainable development, provide access to justice for all and build effective, accountable and inclusive institutions at all levels" (UNESCO, 2017).

Selain itu, penguat lainnya ialah munculnya kesadaran dan urgensinya pendidikan kedamaian menjadi salah satu poin penting dari pasal 3 dalam Peraturan Presiden Republik Indonesia nomor 87 tahun 2017 tentang Penguatan Pendidikan Karakter, yang menyebutkan bahwa dilaksanakannya penguatan pendidikan karakter (PPK) ialah menerapkan nilai-nilai Pancasila, terutama nilai-nilai cinta damai. Reardon (1988) seorang pakar pendidikan kedamaian mempertegas makna sebagai suatu konsep perilaku yang dinamis, berproses aktif, dan menjelaskan suatu kondisi di mana keadilan dapat diraih, tanpa adanya perilaku kekerasan.

Usaha membangun sekolah ramah, yaitu sekolah sebagai institusi yang "aman dan damai serta dapat menjadi pionir institusi antikekerasan" yang lebih mengedepankan kesejahteraan siswa di sekolah (Baswedan, 2016, p. 1; Lama, 2016; Syrjäläinen et al, 2015; Kartadinata, 2016, p. 113; Gerstein et al, 2014; Bangchun, 2013; Sneddon, 2010; Konu \& Rimpelä, 2002; Landau \& Gathercoal, 2000), bertemali dengan kecenderungan perilaku kedamaian sejak dini yang perlu diidentifikasi dan dikembangkan secara tepat dan akurat untuk merespons kebutuhan pemberdayaan siswa (Tang dalam UNESCO, 2017) pada sistem pendidikan pembangunan yang berkesinambungan. Sistem ini diharapkan mampu mengilhami, menyemangati, serta menjadi bagian integral dari upaya pengembangan tatapikir kedamaian siswa. Kedamaian siswa merujuk pada suatu proses perkembangan tatapikir, perilaku, orientasi nilai, upaya memperbaiki keadaan, dan penyelesaian konflik dalam kehidupan siswa untuk menciptakan atau mencapai sebuah keadaan damai dan harmonis. Kedamaian sebagai hasil, merujuk pada proses perkembangan dan bukan titik akhir keadaan dari sebuah proses mencapai damai dan harmonis karena kedamaian merupakan suatu keadaan yang harus dipelihara sehingga selalu berada pada kondisi optimum yang dinamis (Kartadinata, 2014).

Tema penelitian tentang kedamaian siswa SMA di Indonesia, sejauh ini masih terbatas. Di Amerika Serikat, Mayton sejak tahun 2001, 2002, dan 2009, berhasil mengkonstruksi skala teenage nonviolence test (TNT) pendeteksi kecenderungan perilaku kedamaian di kalangan remaja. Dilaporkan sejauh mana remaja mendukung kedamaian. Instrumen TNT dikembangkan oleh Mayton berdasarkan konsep Pacificism (Elliot, 1980), Kool (1990), Kool and Sen (dalam Mayton II, 2009, p. 219), filosofi Mohandas (1957, 1951, 1921) dan Gandian Personality Scale (GPS) yang dikembangkan oleh Hasan dan Khan pada tahun 1983 (dalam Mayton II, 2009, p. 219) yang berfokus pada non-kekerasan (ahimsa), mencari kebijaksanaan dan kebenaran (satyagraha), dan kesiap-sediaan untuk menerima atau mengalami adanya penderitaan (tapasya). Gerstein, et al (2014) menegaskan pentingnya menguji struktur faktorial TNT di AS dan di Hongkong (Gerstein, et al, 2016). Tujuan dari penelitian ini adalah untuk melihat apakah skala pendeteksi kedamaian tersebut berhasil diterjemahkan dan diadaptasi sehingga layak digunakan untuk memastikan kecenderungan kedamaian siswa SMA di Indonesia. Pada akhirnya, adaptasi yang dilakukan ini diharapkan berhasil dan mampu memberikan peluang yang seluasluasnya dalam mengukur kedamaian di kalangan siswa SMA Indonesia serta membandingkannya dengan kecenderungan kedamaian yang telah ada, misalnya di Amerika dan Cina (Mayton, 2009; Bangchun, 2013; Lama, 2016). 
Skala TNT yang dikembangkan oleh Mayton (2001, 2002, 2009) terbagi ke dalam enam dimensi dan tersebar ke dalam 55 item Likert. Dimensi pertama, anti-kekerasan fisik sebanyak 16 item, isinya mengukur kesadaran untuk menolak berbagai bentuk kekerasan perilaku atau ancaman perilaku yang dapat menimbulkan orang lain cedera, upaya memaksa, membatasi, atau menghilangkan perilaku mereka dan mendukung alternatif resolusi konflik (mengakui adanya struktur kepercayaan etis dan moral). Kedua, antikekerasan psikologis sebanyak 16 item, isinya mengukur kesadaran untuk menolak berbagai bentuk kekerasan psikologis berupa perilaku atau ancaman perilaku, hinaan atau cara-cara yang dapat merendahkan harkat martabat manusia baik secara individu maupun kelompok dalam usaha memaksa, membatasi, atau menghilangkan perilaku mereka dan mendukung alternatif resolusi konflik, penolakan secara sadar terhadap perilaku yang berusaha memaksa, penghinaan, intimidasi, atau cara lain yang merendahkan martabat manusia orang atau kelompok lain. Ketiga, memiliki orientasi nilainilai yang aktif (sesuai pemikiran Gandhi). Isinya mengukur kemauan, menampilkan perilaku yang didesain untuk mencapai situasi yang sesuai dengan tujuan, nilai-nilai, dan norma. Keempat, membantu atau berempati, mempunyai minat untuk membantu orang lain dalam tingkat kebutuhan yang kecil sekalipun. Kelima, aktif mencari kebijakan dan berkemauan untuk mengubah konsepsi kebenaran dalam hidupnya (satyagraha). Keenam, bersedia untuk tetap sabar dalam menghadapi kesulitan atau penderitaan (tapasya atau tapa), alih-alih menimbulkan konflik baru yang dapat merugikan.

Mayton (dalam Bangchun, 2013, p. 61) dan Lama (2016, p. 706) melaporkan konsistensi internal yang tinggi untuk lima dari enam dimensi. TNT berkorelasi tinggi dengan 65 item nonviolence test (NVT) yang dikembangkan Kool dan Sen (dalam Mayton, 2009), the Aggression Questionnaire (AQ) yang dikembangkan oleh Buss and Perry (dalam Lama, 2016) dan penilaian diri siswa terhadap kecenderungan agresifnya (Mayton, 2009). Selanjutnya, skala anti-kekerasan fisik dan anti-kekerasan psikologis berkorelasi -0,33 dan $-0,38$ dengan peringkat agresi guru yang diukur pada Formulir Penilaian Guru (BAMED) (Baker, dkk., 1991 dalam Lama, 2016). Skala TNT Mayton merupakan instrumen yang baik, namun menurut Lama (2016) dan Bangchun (2013), gagal menguji skor gender pada setiap itemnya. Selain itu, dijelaskan pula bahwa skala Mayton tidak ada satu pun yang mencoba menilai kecenderungan siswa SMA untuk mengambil tindakan dalam rangka melawan atau memerangi kekerasan struktural yang digagas oleh Gandhi dan Martin Luther King. Pada tahun 2001 Diamond (dalam Lama, 2016; Bangchun, 2013) berhasil mengembangkan nonviolence self-test (NST) dan melengkapi TNT dengan ketiga item yang memuat tentang kemauan untuk mengambil tindakan dalam berjuang atau melawan kekerasan struktural atau memperjuangkan keadilan.

Penelitian ini dilakukan untuk mendapatkan instrumen skala TNT yang terstandardisasi dengan berlatar konteks Indonesia. Kemudian data yang diperoleh dari 1118 orang sampel akan menunjukkan karakteristik yang mungkin relatif sama atau berbeda dari data yang ada sebelumnya berdasarkan sampel remaja Amerika (Mayton, 2009) dan Cina (Bangchun, 2013; Lama, 2016).

\section{METODE}

Sampel acak untuk penelitian ini melibatkan 1118 siswa dari 12 SMA Negeri Kota Bandung terpilih, terdiri atas siswa laki-laki sebanyak 554 (49,55\%) dan siswa perempuan sebanyak $564(50,45 \%)$, dengan standar deviasi data total sebesar 0,50 . 
Survei dilakukan pada awal Januari-Maret 2018. Pertama, penelitian ini melibatkan sekitar 24 orang mahasiswa yang sudah dilatih terlebih dulu dalam memahami instruksi instrumen dan alur penelitian yang akan dilakukan. Jadi setiap sekolah dikunjungi oleh dua orang mahasiswa peneliti. Kedua, menghubungi pihak pimpinan sekolah untuk meminta izin penelitian di sekolah dan menghubungi guru mata pelajaran dan/atau guru bimbingan dan konseling (guru BK)/konselor yang ditunjuk untuk dipergunakan jam pembelajaran/jam layanan BK-nya, beberapa sehari sebelum survei dilakukan. Ketiga, menjelaskan secara rinci di kelas yang menjadi sampel dan menjawab pertanyaan siswa jika ada item-item tertentu yang belum dipahami serta memotivasi siswa untuk mengisi kuesionernya secara saksama dan serius. Rentang waktu yang diperlukan untuk mengerjakan skala TNT sekitar 30-45 menit. Keempat, setelah mengisi kuesioner, masingmasing peserta diberi apresiasi makanan ringan.

Pola penyekoran skala TNT mempunyai rentang dari sangat menggambarkan diri saya (5), menggambarkan diri saya (4), cukup menggambarkan diri saya (3) kurang menggambarkan diri saya (2), dan tidak menggambarkan diri saya (1). Untuk menguji validitas dan reliabilitas item digunakan analisis pemodelan Rasch (Sumintono dan Widhiarso, 2015, p. 51-57) dan Boone (2016, p. 1) yang menegaskan, bahwa: "Rasch analysis is a psychometric technique that was developed to improve the precision with which researchers construct instruments, monitor instrument quality, and compute respondents' performances. Rasch analysis allows researchers to construct alternative forms of measurement instruments, which opens the door to altering an instrument in light of student growth and change. Rasch analysis also helps researchers think in more sophisticated ways with respect to the constructs (variables) they wish to measure..."

\section{HASIL DAN PEMBAHASAN}

\section{Reliabilitas (Konsistensi)}

Indeks reliabilitas person $(0,91)$ termasuk kategori bagus sekali dengan separasi 3,23, artinya pengelompokkan data sudah tepat, makin beragam kelompoknya, sehingga lebih representatif. Indeks reliabilitas item $(0,99)$ termasuk kategori istimewa dengan separasi 12,73 , artinya pengelompokkan data sudah tepat, semakin beragam kelompoknya, atau lebih representatif. Berikutnya, diperoleh indeks reliabilitas interaksi (konsistensi) antara person-item (Alfa Cronbach) sebesar 0,92 termasuk kategori bagus sekali.

Tabel 1. Rangkuman Statistik untuk 1118 Siswa

\begin{tabular}{llllc}
\hline Summary & Mean Logit & Separation & Reliability & Alpha Cronbach \\
\hline Person & 0,26 & 3,23 & 0,91 & \multirow{2}{*}{0,92} \\
\cline { 1 - 3 } Item & 0,00 & 12,73 & 0,99 & \\
\hline
\end{tabular}

\section{Validitas}

Validitas konstruk skala TNT (unidimensionality test) dengan memperhatikan rawvariance diperoleh indeks sebesar 29,0\%, mendekati angka 0,30 (30\%). Hal ini mengandung arti, bahwa item-item pada skala TNT versi Indonesia memiliki kategori yang bagus dalam mengukur keragaman kemampuan responden dan mampu juga mengukur satu variabel secara komprehensif.

Validitas dan Reliabilitas TNT 
Validitas item TNT menghasilkan angka positif pada $\mathrm{p}<0.05$. Artinya validitas seluruh item TNT yang diadaptasi ke dalam budaya Indonesia, dapat dipersepsi secara tepat oleh responden. Adapun nilai alfa Cronbach sebesar 0.89, termasuk kategori bagus (Sumintono dan Widhiarso, 2015, p. 109). Indeks unidimensionalitasnya sebesar 36.5\%, termasuk kategori bagus (Sumintono dan Widiarso, 2014, p. 122).

\section{Konsistensi Internal}

Skala TNT versi Indonesia tampaknya memiliki konsistensi internal yang tinggi untuk tiga dari enam dimensi yang diukur, dengan koefisien alfa Cronbach sebesar 0.85 pada dimensi anti-kekerasan psikologis, sebesar 0.76 pada dimensi anti-kekerasan fisik, serta sebesar 0.72 pada dimensi anti-kekerasan satyagraha. Tiga dari dimensi lainnya cenderung sedang tingkat konsisten internalnya $(\alpha=0.67$ pada dimensi "empati/membantu", $\alpha=0.56$ pada dimensi "tapasya", $\alpha=0.40$ pada dimensi "orientasi nilai-nilai yang aktif"). Lebih jelas hasil ini dapat dilihat pada tabel 1 berikut.

Tabel 2. Konsistensi internal TNT

\begin{tabular}{lllll}
\hline \multirow{2}{*}{ TNT subscale } & \multicolumn{4}{c}{ Alpha coefficient } \\
\cline { 2 - 5 } & $\begin{array}{l}\text { American } \\
(\mathrm{n}=376)^{*}\end{array}$ & $\begin{array}{l}\text { Chinese } \\
(\mathrm{n}=313)^{* *}\end{array}$ & $\begin{array}{l}\text { Indonesian } \\
(\mathrm{n}=2293)^{* * *}\end{array}$ & $\begin{array}{l}\text { Indonesian } \\
(\mathrm{n}=1118)\end{array}$ \\
\hline Physical nonviolence & 0.90 & 0.79 & 0.76 & 0,80 \\
\hline Psychological nonviolence & 0.86 & 0.83 & 0.85 & 0,87 \\
\hline Active value orientation & 0.32 & 0.37 & 0.40 & 0,46 \\
\hline Helping/empathy & 0.80 & 0.63 & 0.67 & 0,73 \\
\hline Satyagraha & 0.77 & 0.65 & 0.72 & 0,77 \\
\hline Tapasya & 0.78 & 0.60 & 0.56 & 0,59 \\
\hline
\end{tabular}

* Mayton, 2009, **Bangchun, 2013, ${ }^{* *}$ Lama 2016, ${ }^{* * *}$ Sudrajat 2017

Tabel 3. Rangkuman Statistik untuk Dimensi Anti-kekerasan Fisik

\begin{tabular}{llllc}
\hline Summary & Mean Logit & Separation & Reliability & Alpha Cronbach \\
\hline Person & 0,08 & 1,87 & 0,78 & \multirow{2}{*}{0,80} \\
\cline { 1 - 3 } Item & 0,00 & 7,46 & 0,98 & \\
\hline
\end{tabular}

Tabel 4. Rangkuman Statistik untuk Dimensi Anti-kekerasan Psikologis

\begin{tabular}{llllc}
\hline Summary & Mean Logit & Separation & Reliability & Alpha Cronbach \\
\hline Person & 0,15 & 2,30 & 0,84 & \multirow{2}{*}{0,87} \\
\hline Item & 0,00 & 12,14 & 0,99 & \\
\hline
\end{tabular}

Tabel 5. Rangkuman Statistik untuk Dimensi Nilai-nilai yang Aktif

\begin{tabular}{llllc}
\hline Summary & Mean Logit & Separation & Reliability & Alpha Cronbach \\
\cline { 1 - 3 } Person & 0,66 & 0,84 & 0,45 & \multirow{2}{*}{0,46} \\
\hline Item & 0,00 & 13,44 & 0,99 & \\
\hline
\end{tabular}

Tabel 6. Rangkuman Statistik untuk Dimensi Empati

\begin{tabular}{lllll}
\hline Summary & Mean Logit & Separation & Reliability & Alpha Cronbach \\
\cline { 1 - 4 } Person & 0,67 & 1,41 & 0,66 & \multirow{2}{*}{0,73} \\
\cline { 1 - 3 } Item & 0,00 & 12,30 & 0,99 & \\
\hline
\end{tabular}


Tabel 7. Rangkuman Statistik untuk Dimensi Satyagraha

\begin{tabular}{llllc}
\hline Summary & Mean Logit & Separation & Reliability & Alpha Cronbach \\
\cline { 1 - 3 } Person & 0,72 & 1,49 & 0,69 & \multirow{2}{*}{0,77} \\
\cline { 1 - 3 } Item & 0,00 & 12,58 & 0,99 & \\
\hline
\end{tabular}

Tabel 7. Rangkuman Statistik untuk Dimensi Tapasya

\begin{tabular}{llllc}
\hline Summary & Mean Logit & Separation & Reliability & Alpha Cronbach \\
\cline { 1 - 4 } Person & 0,54 & 1,14 & 0,57 & \multirow{2}{*}{0,59} \\
\cline { 1 - 3 } Item & 0,00 & 10,04 & 0,99 & \\
\hline
\end{tabular}

Dengan memperhatikan dinamika indeks reliabilitas dan validitas yang diperoleh, tampaknya skala TNT versi Indonesia cukup menjanjikan, karena memiliki konsistensi internal yang bagus sekali dengan koefisien alfa Cronbach $(\alpha=0,92)$. Item-item pada skala TNT versi Indonesia bagus dalam mengukur keragaman kemampuan responden dan mampu mengukur satu variabel secara komprehensif.

Sangat menarik untuk memeriksa kembali mengapa hampir semua item TNT versi Indonesia (55 item) dapat digunakan. Dalam hal ini, sekitar 1118 orang responden merespons secara tepat. Artinya 1118 siswa SMA mempunyai persepsi yang sama dan instrumennya sendiri tepat dalam merumuskan tiap dimensi skala TNT sehingga instrumen ini dapat diandalkan. Skala TNT versi Indonesia telah berhasil mengukur kecenderungan perilaku kedamaian.

Salah satu kelebihan penelitian ini ialah jumlah responden yang cukup besar, namun bagaimanapun masih tetap ada beberapa keterbatasan. Pertama sampelnya berasal dari satu kota dari beberapa sekolah terpilih yang diambil berdasarkan simple random sampling sehingga informasinya belum lengkap dan utuh. Kedua, reliabilitas uji coba, koefisien konkuren dan validitas kelompok di antara kelompok siswa SMA belum disempurnakan oleh konteks dimensi, gender, usia, dan kelas. Ketiga, validitas TNT belum dinilai atau dibandingkan dengan skala yang lainnya. Keempat, masih ada peluang ketidaksesuaian menempatkan semua item TNT Amerika untuk digunakan langsung dalam konteks dan budaya Indonesia.

\section{SIMPULAN}

Terdapat beberapa hal penting dan menarik untuk melakukan penelitian skala TNT di masa depan dalam konteks Indonesia. Pertama, diperlukan untuk mengetahui validitas dan reliabilitas TNT dengan jumlah sampel yang lebih banyak di antara siswa SD, SMP, SMK, dan santri di pesantrenan, baik di kota maupun di pedesaan. Kedua, validitas konkuren TNT akan dinilai dengan skala yang berbeda, misalnya Pacifism Scales yang dikembangkan oleh Elliot (1980), Nonviolence Test (NVT) yang dikembangkan oleh Kool dan Sen (1984), Gandhian Personality Scale (GPS) yang dikembangkan oleh Hasan dan Khan (1983), Multidimensional Scales of Nonviolence (MSN) yang dikembangkan oleh Johnson et al, The Nonviolent Relationship Questionnaire (NVRQ) yang dikembangkan oleh Eckstein dan La Grassa (2005), "Self-Asssessment" of Nonviolence, Nonviolence Self-Inventory yang dikembangkan oleh French (2004), Self-Test on Nonviolence yang dikembangkan oleh 
Diamond (2011), Nonviolence Inventory of Your Home and Family yang dikembangkan oleh Diamond (2001) seperti halnya yang disarankan oleh Sudrajat (2017).

Dengan demikian, sangat dibutuhkan untuk merancang lebih banyak skala kedamaian di Indonesia dengan berbagai dimensi, selain nilai-nilai inti kedamaian dan hidup harmoni yang telah dikembangkan lebih dulu oleh UNESCO dan UPI (2000). Penelitian ini menunjukkan sebuah dinamika pergerakan dan kemajuan, serta menjadi tahap kedua yang baik bagi pengembangan skala TNT dalam konteks Indonesia yang kaya etnis.

\section{REFERENSI}

Bangchun, L. (2013). The Peacefulness of Chinese Teenagers. International Journal of Educational, 2(3), 60-66.

Baswedan, A. (2016). Permendikbud 82/2015: Pencegahan dan Penanggulangan Tindak Kekerasan di Lingkungan Satuan Pendidikan. Jakarta: Kemendikbud RI.

Baswedan, A. (2016). Mendikbud canangkan sekolah anti kekerasan. Retrieved January 25th, 2018, from http://sp.beritasatu.com/home/mendikbud-canangkan-sekolah-antikekerasan/106918.

Boone, W. J. (2016). Rasch analysis for instrument development: Why, when, and how? CBE Life Sciences Education, 15(4), 1-7. doi: 10.1187/cbe.16-04-0148

Elliot, G. C. (1980). Components of pacifism: conceptualization and measurement. Journal of Conflict Resolution, 24, 27-54. doi:10.1177/002200278002400102.

Gerstein, L. H., Chan, Y., Hutchison, A., Fung, A. L. C., Kinsey, R., \& Jeffers, H. (2018). The Teenage Nonviolence Test: Applicability in Hong Kong?. Current Psychology, 37(1), 313-324.

Gerstein, L. H., Mayton, D., Hutchison, A. N., \& Kirkpatrick, D. (2014). The teenage nonviolence test: a factor analytic investigation. Revista de Cercetare si Interventie Sociala, 44, 9-19.

Kantor Prinsipal UNESCO untuk Kawasan Asia-Pasifik Bangkok dan Universitas Pendidikan Indonesia. (2000). "Belajar untuk hidup bersama dalam damai dan harmoni: pendidikan nilai untuk perdamaian, hak-hak asasi manusia, demokrasi, dan pembangunan berkelanjutan untuk kawasan Asia-Pasifik". Buku sumber UNESCO-APNIEVE untuk pendidikan guru dan jenjang pendidikan tinggi. Bandung: Universitas Pendidikan Indonesia.

Kartadinata, S. (2016). Reveal the veil of guidance and counseling in pedagogic effort. Bandung: UPI Press.

Kartadinata, S. (2014). Pendidikan untuk kedamaian dan pendidikan kedamaian (education for peace and peace education). Bandung: UPI Press.

Konu, A \& Rimpelä, M. (2002). Well-being in schools: A conceptual model. Health Promotion International, 17(1), 79-87.

Lama, D. C. (2016). Peacefulness of Chinese teenagers in a high school. International Journal of Educational Research and Reviews, 705-711. 
Landau B. M. \& Gathercoal, P. (2000). Creating peaceful classrooms. Judicious Discipline and Class Meetings, 450-454.

Lubelksa, A. (2012). Peaceful schools. International Journal of Children's Spirituality, 17(2), 187-191.

Majelis Luhur Persatuan Taman Siswa. (2013). Ki Hadjar Dewantara: pemikiran, konsepsi, keteladanan, sikap merdeka. Yogyakarta: Universitas Sarjanawiyata Taman Siswa (UST) Press.

Mayton, D. M. (2001). Nonviolence within cultures of peace: A means and an ends. Peace and Conflict. Journal of Peace Psychology, 7, 143-155. doi: 10.1207/S15327949PAC0702_05.

Mayton, D. M. (2013). CMP's focus on a peaceful school environment: A proactive approach to prevent bullying in our schools.

Mayton, D. M., \& Palmer, B. J. (1996). The measurement of nonviolence. 1-16.

Mayton, D. M. (2009). Measurement Tools for Research on Nonviolence and Related Concepts. In Nonviolence and Peace Psychology (pp. 219-237). Springer, New York, NY.

Mayton, D. M., et al. (2001). Nonviolent tendancies of adolescents across gender and grade. Journal of Nonviolent Tendancies of Adolescents, 3-14.

Mayton, D. M., Richel, T. W., Susnjic, S., \& Majdanac, M. (2002). Measuring the nonviolent tendencies of college students (pp.1-17). Paper presented at the 110th annual meeting of the American Psychological Association, Chicago IL, USA, August 23, 2002.

Peraturan Presiden Republik Indonesia Nomor 87 Tahun 2007 tentang Penguatan Pendidikan Karakter.

Reardon, B. (1988). Comprehensive peace education. New York. Teacher College. Columbia University.

Sneddon, S. (2010). The peaceable classroom. Retrieved January 25th, 2019, from http://www.promotingpeace.org/2010/3/sneddon.html.

Sumintono, B., \& Widhiarso, W. (2014). Aplikasi model rasch untuk penelitian ılmu-ilmu sosial. Cimahi: Trim Komunikata Publishing House.

Sumintono, B. (2018). Workshop Lanjutan Pemodelan Rasch di Departemen PPB FIP UPI (Bahan Presentasi). Bandung: 23-24 Maret 2018.

Syrjäläinen, E., Jukarainen, P., Värri, V. M., \& Kaupinmäki, S. (2015). Safe school day according to the young. Young, 23(1), 59-75.

UNDP. (2000). Sustainable Development Goals: In 2000, 189 Countries of The World Came Together To Face The Future. New York: UNDP.

UNESCO. (2017). Education for sustainable development goals learning objective. Paris: UNESCO. 